Johannes Wunderlich, Katy Armstrong, Georg A. Buchner, Peter Styring, Reinhard Schomäcker

\title{
Integration of techno-economic and life cycle assessment: Defining and applying integration types for chemical technology development
}

Journal article | Accepted manuscript (Postprint)

This version is available at https://doi.org/10.14279/depositonce-11485

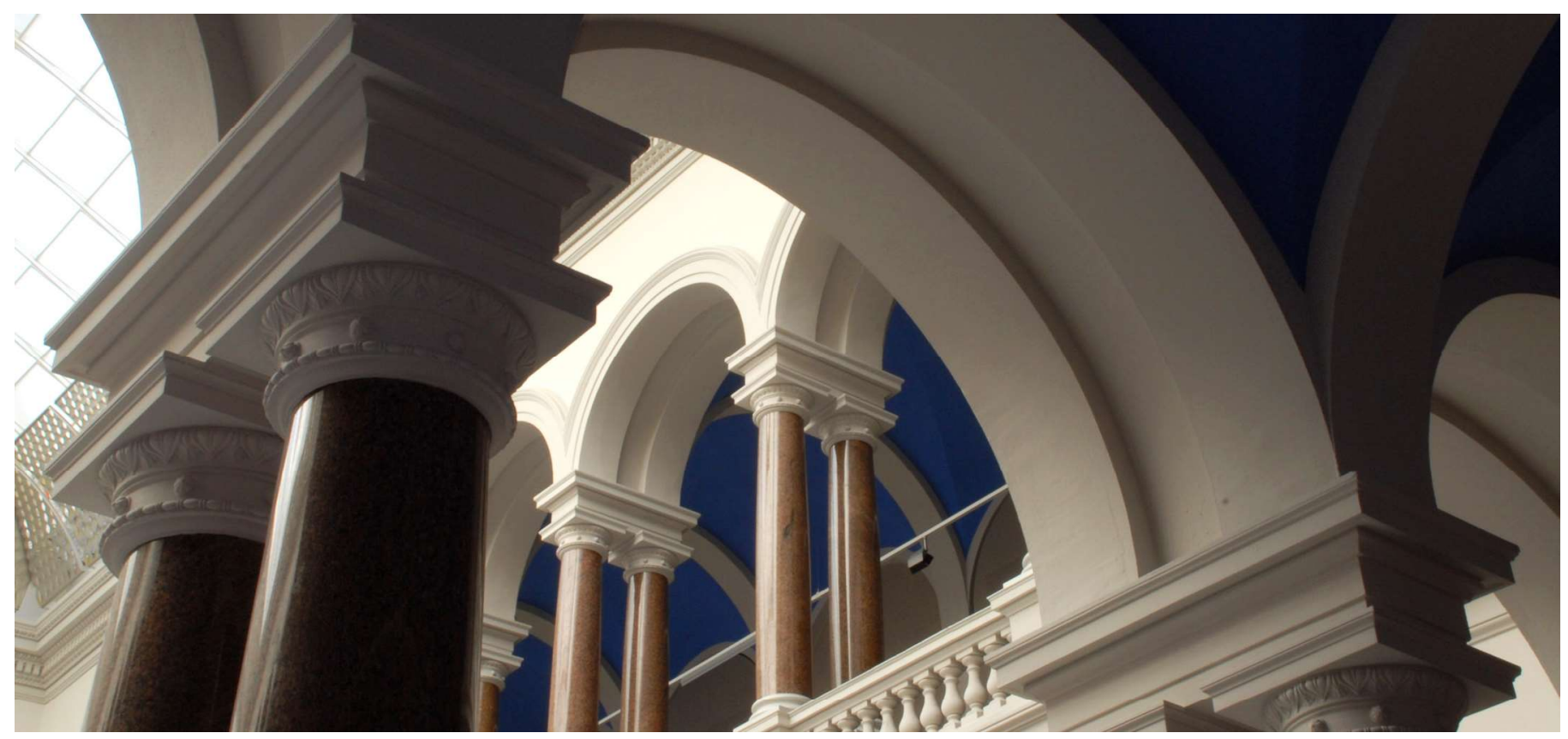

Wunderlich, J., Armstrong, K., Buchner, G. A., Styring, P., \& Schomäcker, R. (2021). Integration of techno-economic and life cycle assessment: Defining and applying integration types for chemical technology development. Journal of Cleaner Production, 287, 125021.

https://doi.org/10.1016/j.jclepro.2020.125021 


\title{
Integration of techno-economic and life cycle assessment: defining and applying integration types for chemical technology development
}

\author{
Johannes Wunderlich*a, Katy Armstrong ${ }^{\star b}$, Georg A. Buchner ${ }^{c}$, Peter Styring ${ }^{b}$, Reinhard \\ Schomäcker ${ }^{\mathrm{a}}$ \\ a Department of Chemistry, Technische Universität Berlin, Straße des 17. Juni 124, 10623 Berlin, Germany \\ ${ }^{\mathrm{b}}$ UK Centre for Carbon Dioxide Utilisation, Department of Chemical \& Biological Engineering, University of \\ Sheffield, Sir Robert Hadfield Building, Sheffield, S1 3JD, United Kingdom \\ c TUM Campus Straubing for Biotechnology and Sustainability, Technical University of Munich, Am \\ Essigberg 3, 94315 Straubing, Germany
}

\begin{abstract}
Both an environmental and an economic assessment are needed to judge the potential of sustainable chemical technologies. However, decision-makers may be challenged by conflicting conclusions. The integration of life cycle assessment (LCA) and techno-economic assessment (TEA) can enhance decision-making, as integrated assessments provide more information than a simple reporting of separate TEA and LCA results. The analysis of integration approaches reveals a lack of consistency in terms of defining criteria and methodological aspects for integration. A gap remains where guidance for practitioners is needed on how to select a suitable integration type for their different purposes. To fill this gap, we conclude that a one-size-fits-all solution of integration cannot adequately serve all purposes along the technology development phases. Therefore, a framework to guide through integration in three distinct parts is proposed. In Part I, a four-phase approach for every integrated assessment to link the results from TEA and LCA is defined. Part II develops three integration types classified by their core characteristics: qualitative discussion-based (Type A), quantitative combined indicator-based (Type B), and quantitative preferences-based (Type C). Finally, in Part III, a step-by-step method to select the appropriate integration type according to the assessment purpose, while considering restrictions imposed by technology maturity and resource availability is introduced. Thus, the framework is a basis for increasing the number of integrated assessments by guiding practitioners towards tailored studies.
\end{abstract}




\section{Introduction}

\subsection{General principles of techno-economic assessment and life cycle assessment}

The call for sustainable processes within the chemical industry necessitates measures to ascertain economic viability and the level of environmental impacts (Zimmerman et al., 2020). Despite the importance of social impacts as third sustainability dimension, these are left outside the scope of this work which focuses on established practices in research and development. Techno-economic assessment (TEA) and life cycle assessment (LCA) are commonly used methodologies to assess underlying criteria individually. However, decision-making in technology development should not be made from either the economic or the environmental perspective alone (Norris, 2001a). Sound decision-making requires an understanding of the trade-offs which is not fully developed if only a separate reporting of TEA and LCA results is available. In contrast, integrated assessments intend to derive combined goal-driven insights by specifically describing the interdependencies of the indicator results (van der Sluijs, 2002). Therefore, in this work, integration of TEA and LCA is defined as the selection and processing of available information from both assessments to prepare a meaningful interpretation shining light on how TEA and LCA results are linked.

TEA and life cycle costing (LCC) (Hunkeler et al., 2008; Swarr et al., 2011) can be defined as methodology frameworks that provide systematic approaches for assessing the economic viability of a technology as depicted in Figure 1. TEA is typically limited to an inherent investor-perspective with cradle-to-gate system boundaries, whereas LCC's inherent perspective aims at cost analysis along all life-cycle stages of a product (Miah et al., 2017). Both TEA and LCC methodologies can be adapted to include further optional perspectives. This paper focusses on TEA because of its strong relation to technology development in the chemicals industry (a detailed methodological comparison of TEA and LCC is provided in the Electronic Supporting Information). Integral parts of TEA are cost and market analysis to provide data for profitability indicators. Optionally, TEA entails the reporting of selected technical parameters in the context of technology development. TEA methodology is not standardized and requires to be tailored to each case. However, a fourphase approach guiding the assessment has been proposed that is also inherent to LCA (Buchner et al., 2018; Zimmermann et al., 2020a). LCA methodology is standardized by ISO 14040/44 (International Organization for Standardization [ISO], 2006a, 2006b). Further guidance for LCA is available, for example in the ILCD handbook (European Commission - Joint Research Centre Institute for Environment and Sustainability, 2010) and the handbook on life cycle assessment (Guinée et al., 2002). Due to methodological overlaps with TEA, the focus in this paper lies on the type 'process LCA' (Guinée et al., 2011) which will be referred to as 'LCA' only. When applying TEA or LCA to technology development, methodological choices should match data availability within the three innovation phases: applied research, development and deployment (RD\&D). The technology maturity along RD\&D can be expressed by nine technology readiness levels (TRLs), reflecting the available information according to specific criteria (Buchner et al., 2019). 


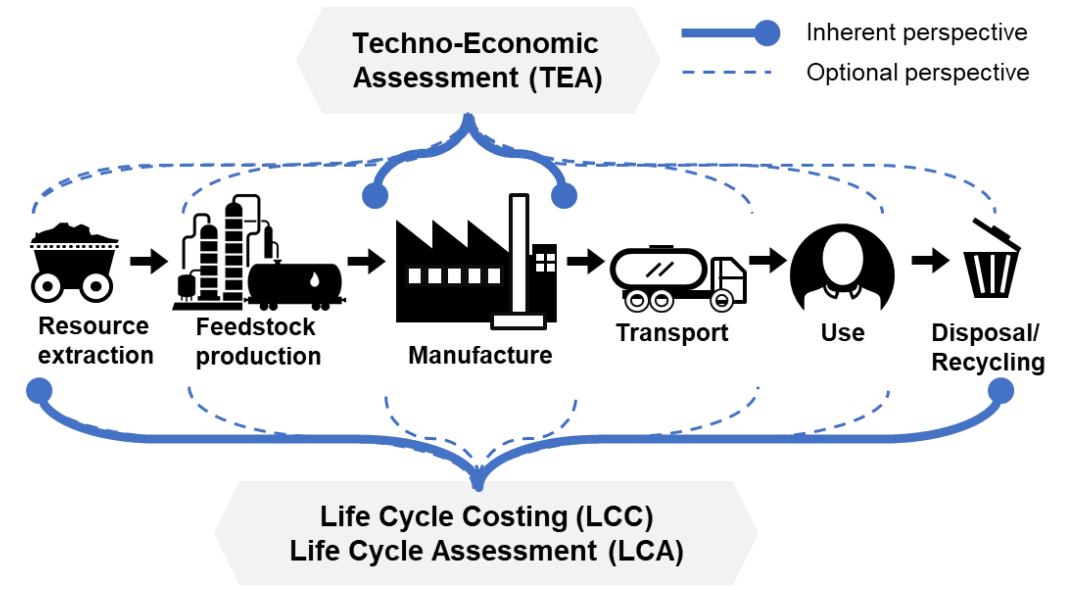

Figure 1: Product life cycle depicting inherent perspectives of TEA (investor-perspective within manufacturing gates) and LCC and LCA (full-life cycle perspective for all actors); both TEA and LCC can equally cover any combination of stages

\subsection{Concepts for combining economic and environmental assessment and remaining gaps in literature}

Norris (2001a, 2001b) highlights the need for private industry to take into account economic implications when applying LCA to characterize relationships and trade-offs between both dimensions. The work informs about the successful implementation of the concept of total cost assessment (TCA) within several industrial companies (CWRT, 1999). TCA aims at including often hidden internal, and optionally external, cost items incurred by environmental and health-related issues into cost estimation practices of companies. The method intends to consider the perspectives of various stakeholder groups and to include costs of manufacturing, future and contingent liability costs as well as external costs borne by the society including the deterioration of the environment. By methodologically linking data from cost analysis with life cycle assessment results, companies are reported to benefit from better-informed investment decisions. However, a discussion of suitable ways for interpretation of the aggregated economic and environmental results is not presented.

Azapagic et al. (2006) focus on process design stages and highlight the importance of a suitable indicator selection if multiple target audiences with conflicting interests need to be informed by the integrated assessment. The authors propose to integrate environmental and economic results in one indicator, representing environmental impact per value added. The method aims at applying the tools at all life cycle stages, however, the authors acknowledge that most assessments are limited to the plant operation. Santoyo-Castelazo and Azapagic (2014) extend their integration approach by presenting a decision-support framework that requires a multi-criteria decision analysis allowing to include preferences.

Life cycle sustainability assessment (LCSA) has been introduced as a broad framework to combine models for economic, environmental and social assessments (Finkbeiner et al., 2010; Minkov et al., 2016). Guinée et al. (2011) argue that LCSA is a form of integrated assessment as defined by van der Sluijs (2002), because it serves the intention of combining, interpreting and communicating interdisciplinary information from at least two sustainability dimensions. Miah et al. (2017) consider LCSA to be an overarching framework that may not be suitable for decisionmakers focusing on TEA and LCA due to the required information from additional assessments. 
Hoogmartens et al. (2014) include social life cycle assessment (SLCA) to cover all sustainability dimensions. Along with explaining the linkages within the complementary methods of their framework the authors acknowledge that more comprehensive tools need to be developed, as complexity in methodological choices adds to confusion among practitioners, for example, if tradeoffs call for conflicting actions.

Miah et al. (2017) classify six types for integrating different aspects of LCC and LCA. Based on the selection of specific methods, the authors suggest a hybridized framework with four iterative stages. Despite providing a decision-tree, the framework implies a one-size-fits-all solution covering all identified types that would result in choosing a similar integration approach across all possible assessment goals.

Thomassen et al. (2019) propose a prospective 'environmental techno-economic assessment (ETEA)'. Based on TRLs, the authors summarize streamlining strategies for different maturity stages, namely, qualitative methods for TRLs 1-3 and quantitative methods for TRLs 4-9. The dichotomy of qualitative vs. quantitative methods is the only presented difference in the way studies are integrated; the remainder of the ETEA methodology affects calculations within every single assessment. Harmonization and transparency of TEA and LCA regarding data and scope definition is discussed as the leading criterion for integration.

Ibáñez-Forés et al. (2014) analyzed the stages of decision-making in technology assessment with a focus on how to select criteria from multiple perspectives. The authors point out, that in about one third of the reviewed studies the decisions are derived directly from the indicators by numeric or graphic means. In the remaining part, a form of multi-criteria decision analysis is applied to aggregate the indicators.

The discussed literature currently presents a variety of perspectives on which are the key steps for combining economic and environmental assessments. For example, some studies focus on the step of selecting appropriate criteria, whereas others discuss integration in the light of newly combined indicators or the inclusion of preferences via multi-criteria decision analysis. Furthermore, a number of studies are limited to a rigid methodology for integrating TEA and LCA that need to be compliant with an overarching framework, such as LCSA or TCA. While the suitability of each of the frameworks for their particular purpose is acknowledged, these can be considered as top-down solutions that each do not cover the entire sphere of potential integration purposes. There is a lack of guidance for selecting an appropriate integration approach from these methods. Here, the knowledge gap remains in how practitioners can approach an integration of TEA and LCA from the bottom up to subsequently tailor methodological choices to the decisionmaking problem of the target group. Despite an increasing number of contributions in this field, there is no commonly followed definition of the term integration, nor is the integration of TEA and LCA equally understood as an individual assessment that follows a set of general principles.

\subsection{Aim of this work and research methodology}

The aim of this work is to design a holistic framework enabling practitioners to select an appropriate approach for integrating TEA and LCA for the assessment of chemical processes. To provide guidance, first a general structure of integrated assessments will be derived, followed by the definition of integration types and the development of a step-by-step procedure to select a suitable type for different integration purposes. The novel contribution comprises the definition of a set of minimum criteria that have to be met for TEA and LCA to be integrated.

The framework is based on exploratory research conducted in three steps: 
1. Explore studies that combine economic and environmental assessments in technology development,

2. Analyze integration methods to answer the following questions:

a. What are the core characteristics of the integration methods applied in literature?

b. How does the underlying integration purpose influence the selection of the integration method?

c. Which other common characteristics of the objects of analysis influence the selection of the integration method?

3. Develop a framework that enables the selection of a suitable approach to integrate TEA and LCA from the bottom-up.

\section{Analysis of studies combining TEA and LCA}

\subsection{Methodology of analysis}

As described, numerous methodological concepts with different requirements and complexities have been proposed to combine TEA and LCA. However, the question arises as to what methodologies are currently applied in practice and which common characteristics can be derived to guide practitioners in their methodological choice.

To answer this, an exploratory research approach was chosen to analyze academic literature until a theoretical point of saturation was reached (Saunders et al., 2018). Saturation was determined once no further new methodologies or characteristics occurred despite increasing the number of analyzed studies. Studies to be analyzed were randomly selected from a base search to ensure an unbiased representation of the approaches used across academic studies in this area. Random selection was chosen, as it is recognized that the limitation by criteria such as citation number or publication date may produce biased results. The intention was to avoid overrepresentation of works that are cited based on the technology area investigated and not the assessment methodology applied (focus of this work), or of works that are only representative for a limited time frame.

An initial Web of Science search was conducted within the selectable Web of Science categories of 'green sustainable science technology', 'energy fuels' and 'engineering chemical' and the search queries within the title, abstract or keywords of ("LCA" or "life cycle assessment" or "life cycle analysis") and ("TEA" or "LCC" or "life cycle cost" or "economic"). The results were manually screened to remove papers not within the scope of chemical process technologies, producing a set of 711 papers. From this set, papers were randomly ordered using computer-generated random selection. Firstly, each paper underwent further screening to ensure that it contained both economic and environmental assessments and was not of review character, otherwise, they were discarded $(>50 \%$ of papers were discarded in this manner). Subsequently, the paper was analyzed in detail to ascertain the goals, methodologies used, indicators calculated and style of interpretation. Theoretical saturation of methodologies and characteristics was reached at a sample size of 50 papers. To confirm saturation a set of further 20 papers was analyzed. A summary listing the 70 papers and results of the analysis is provided in the Electronic Supporting Information. 


\subsection{Identified characteristics of combining TEA and LCA}

\subsubsection{Purpose}

The analysis found that the purpose for combining TEA and LCA can vary substantially, for example:

- separately reporting environmental and economic impacts of a whole process;

- assessing hotspots of a single process (often in comparison to an existing technology);

- assessing alternative options for process design, feedstock or product applications;

- performing non-detailed comparisons of different technologies to assess the best fit to the goal.

\subsubsection{Approach}

No standard approach is observed for combining economic and environmental impacts. In many cases, economic and environmental impacts were reported separately and the purpose of the study did not necessitate linkages between indicators to be explored in detail. Those papers directly comparing alternative technologies tend to use a quantitative method of integrating economic and environmental results, such as combined indicators or multi-criteria decision analysis:

\section{Combined indicators are applied for technology comparisons}

When combined economic and environmental indicators are calculated, the predominant indicator used is carbon abatement cost which occurs in 11 of the 21 papers calculating combined indicators; for example in Telsnig et al. (2013) and Verma et al. (2015). This is unsurprising due to the impetus on reducing global GHG emissions and economic disincentive mechanisms such as carbon pricing or taxes. Hence, determining the process design option that delivers minimal carbon abatement costs is advantageous both from corporate and policy makers' perspectives. Applied as a useful comparison method, a wider range of combined economic indicators is suggested in Mata et al. (2015) and Halog and Manik (2011).

\section{Multi-criteria approaches}

30 papers use a multi-criteria decision analysis (MCDA) or multi-objective optimization (MOO) approach for the integration of the economic and environmental results to enable preferencebased weighting and aggregation of environmental and economic impacts; for example García et al. (2014) and Tock and Maréchal (2015). Methodologies observed range from simple ranking systems that aggregate the results to select the preferred alternative (MCDA), to mathematical optimization techniques that identify a set of optimal alternatives (MOO). In the sample, MOO is most commonly applied for Pareto-curves (Marler and Arora, 2004) which present a set of scenarios that each cannot be improved in one dimension without worsening the other. MCDA (Velasquez and Hester, 2013) is mostly applied via analytical hierarchy processes (AHP) by using pair-wise comparisons to estimate criteria weights. As methodology choice remains a difficult task for the practitioner, frameworks have been suggested to assist selection, for example, Guitouni and Martel (1998) and Wątróbski et al. (2019). A small number of papers present examples for applying a specific MCDA approach within a larger framework to support decision-makers (Gargalo et al., 2017; Halog and Manik, 2011; Zhang et al., 2016). Some papers employ a combination of combined indicators and MCDA methods; for example Gargalo et al. (2017), Reich (2005), Tock et al. (2015) and Bernier et al. (2010). 


\subsubsection{Further characteristics}

Overall, a number of common characteristics were identified across the analyzed literature:

\section{Goals of the assessments are generalized}

It was observed that in 44 papers a general type of a combined economic and environmental goal is stated, often in the style of 'the aim of the study is to evaluate the economic and environmental impacts of the process'. This type of generalized goal does not elucidate whether the interactions of the economic and environmental impacts will be discussed, nor does it provide significant detail as to unambiguously describe the goal as required in ISO 14040 for LCA. The remaining papers state a combined goal in the introduction to the work and further define separate sub-goals before the individual economic and environmental assessment sections of the paper. Examples of this include Thomassen et al. (2018) and Chao et al. (2019). Largely, these LCA/TEA sub-goals are more detailed tending towards ISO 14040 requirements. However, a statement of the intended audience or stakeholders for the study is not common, except for some cases such as Khatiwada et al. (2016).

\section{Discussions of the linkages between environmental and economic impacts vary}

The analysis highlighted there is variation in the discussion of the linkage between economic and environmental impacts, and that sensitivity and uncertainty analysis are not applied uniformly. In 27 of the 70 papers, the impacts are interpreted separately after their individual analysis and their interactions with each other are not expressed beyond a couple of sentences; for example, Pastore et al. (2016), Di Maria et al. (2018), García-Velásquez and Cardona (2019). Papers that include MCDA were predictably found to have the most detailed interpretation of the linkages, as this is the objective of such analysis. These papers use graphical representations, diagrams, matrices, and tables mixed with written discussion to show the relationship between the economic and environmental indicators; examples are Tock and Maréchal (2015) and Lu and El Hanandeh (2019).

\section{Technology Readiness Level (TRL) concept is not widely used in scope definitions}

The maturity of the technology has a significant impact on the quality of the data and uncertainty of the analysis and therefore a definition of the assessed technologies maturity is of great benefit when determining how integration can be applied (Buchner et al., 2018; Moni et al., 2020; Zimmermann et al., 2020a). Only three mentions of the TRL concept were found throughout the analyzed papers. Maturity of the technology was discussed in 17 of the papers, using terms such as 'immature' (Tang and You, 2018) and 'emerging' (Halog and Manik, 2011). However, these terms are broad and could imply the whole range of development stages from laboratory to demonstration scale. Therefore, it is surprising that a clear definition of the maturity of the assessed process by a standardized methodology, such as TRL, is not included. The TRL concept is widely recognized and often used in industry and scientific mechanisms such as EU Horizon 2020 since 2014; as 46 of the papers have been published since 2014 it is unexpected to not see it more widely applied in academic research. 


\section{Development of the integration framework}

\subsection{Conceptualization}

A major finding from the literature analysis is the great variety of approaches to combine economic and environmental assessments. However, these can be characterized and sorted into a number of discrete integration activities. In general, the activities can be differentiated into qualitative or quantitative approaches. It was found that the goal of the study affects the depth to which TEA and LCA are combined, indicating the importance of articulating this clearly. Furthermore, the literature review of current frameworks showed that practitioners planning the integration of TEA and LCA lack early guidance as to whether a qualitative or quantitative approach is suitable for their individual purpose (goal). Hence, a framework is derived to provide a systematic pathway to find the fitting integration activity. This equips practitioners with key underlying principles and enables them to manage the variety of methodological choices. The framework is derived consisting of three parts:

- Part I defines key aspects of integrated assessment,

- Part II defines integration types,

- Part III presents an approach to select a suitable integration type.

As the specific terminology related to the topic of integration varies in the literature, the relevant terms used in this paper are described in Table 1.

Table 1: Descriptions of concepts used in this contribution: integration, alignment, combination, aggregation, composition.

\begin{tabular}{|c|c|}
\hline & \\
\hline $\begin{array}{l}\text { Integrated } \\
\text { assessment }\end{array}$ & $\begin{array}{l}\text { Integration can be defined as the incorporation of elements as equals into a } \\
\text { group (Merriam-Webster.com Dictionary, } 2020 \mathrm{a}) \text {. } \\
\text { TEA and LCA are separate elements with equal rank in the superordinate } \\
\text { integrated assessment. }\end{array}$ \\
\hline $\begin{array}{l}\text { Alignment of } \\
\text { scope/inventory }\end{array}$ & $\begin{array}{l}\text { Alignment can be defined as a specific arrangement of groups in relation to } \\
\text { one another (Merriam-Webster.com Dictionary, 2020b). } \\
\text { Alignment in the context of this contribution inherently refers to a high level of } \\
\text { similarity of the information underlying each group. } \\
\text { Aligned scope between TEA and LCA refers to the high similarity of system } \\
\text { boundaries, selected allocation methods, geographical and temporal context. } \\
\text { Aligned inventory refers to all data required in both TEA and LCA such as } \\
\text { common material or energy balances from assessed process design. }\end{array}$ \\
\hline $\begin{array}{l}\text { Combined } \\
\text { goal/indicator }\end{array}$ & $\begin{array}{l}\text { Combining can be defined as individual entities becoming one number or } \\
\text { expression (Merriam-Webster.com Dictionary, } 2020 \mathrm{c}) \text {. } \\
\text { Here, a combined goal refers to a single goal of one study with the purpose } \\
\text { of integrating TEA and LCA results. } \\
\text { A combined indicator is a new indicator formed by the division or multiplication } \\
\text { of one environmental and one economic value (e.g., carbon dioxide } \\
\text { abatement cost }\left[\$ / \mathrm{kg} \mathrm{CO} \mathrm{CO}_{2} \text { eq abated], acidification per added value [kg } \mathrm{SO}_{2}\right. \\
\text { eq } \$ \text { ]) and can be characterized by its two-dimensional unit, the similarity to } \\
\text { eco-efficiency (EE) indicators and the alternative term composite indicator }\end{array}$ \\
\hline $\begin{array}{l}\text { Aggregated } \\
\text { indicator }\end{array}$ & $\begin{array}{l}\text { Aggregation can be defined as many parts composed to a single body } \\
\text { (Merriam-Webster.com Dictionary, } 2020 \mathrm{~d} \text { ). }\end{array}$ \\
\hline
\end{tabular}




\subsection{Part I - key aspects of an integrated assessment}

The purpose of integration is to give indications for a subsequent decision-making step within the overall progression of technology development and assessment. Thus, the focus must be on the interaction between the TEA and LCA indicators. Integration can be operationalized in the form of an individual, overarching assessment combining subordinate TEA and LCA. Such integrated assessments can be approached with the same four phases (I-IV) that apply to single TEAs or LCAs as depicted in Figure 2: Goal and Scope (I), Inventory (II), Impact Calculation (III), Interpretation (IV). Within this multi-layer assessment structure, integration is superordinate, relying on a well-balanced subordinate TEA and LCA to feed the inventory of the integrated assessment. Thus, whether the resulting integration complexity is high or low is inter-dependent on what can be provided by the scopes of TEA and LCA. Between the individual phases, iterations are possible to refine the assessment. After completing the assessment, the interpreted results are used to support decision-making which can affect different areas, such as process design or investments into specific technologies, and potentially start a new assessment iteration. Key aspects of the four phases of integrated assessments will be discussed in the following paragraphs.

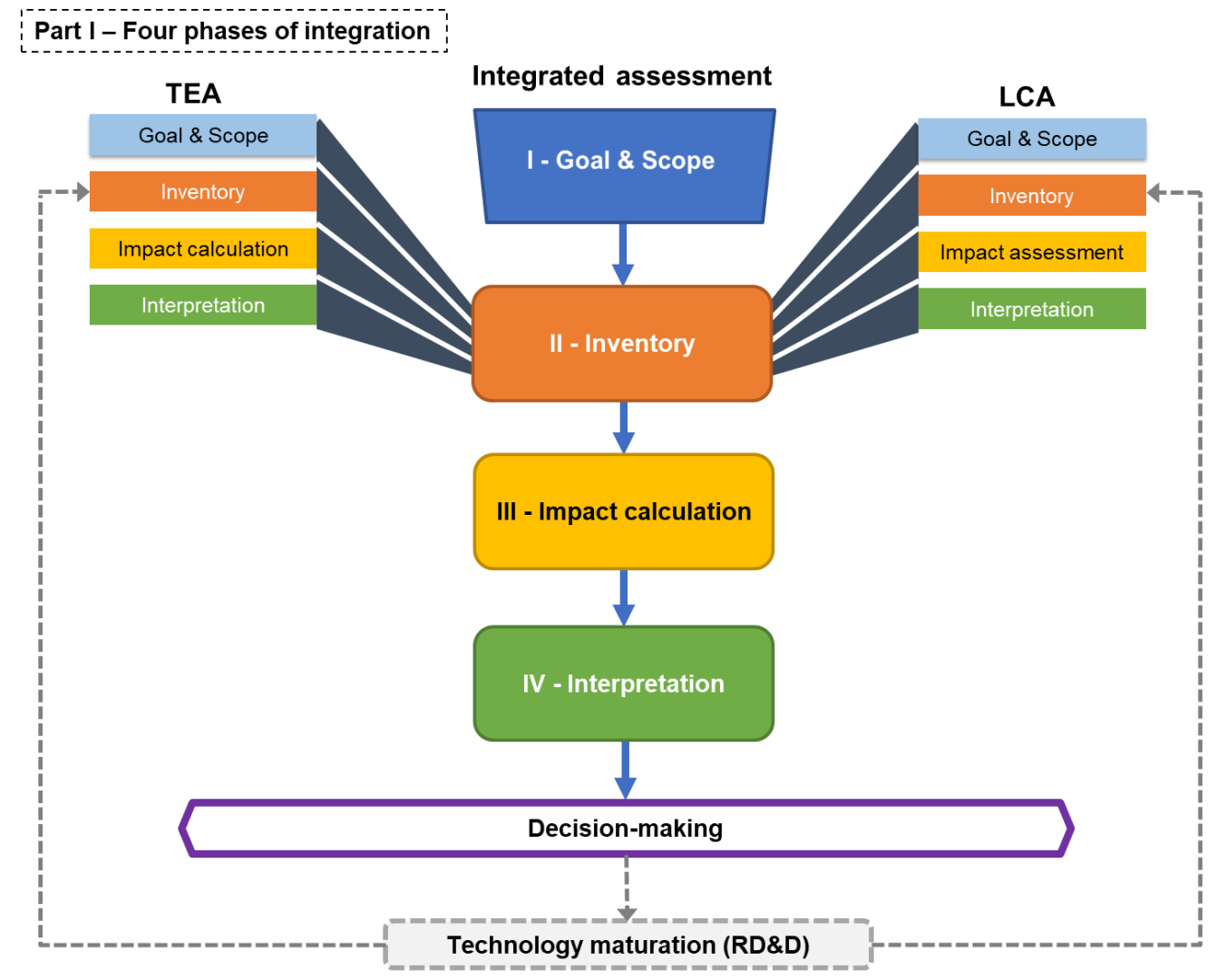

Figure 2: Part I of the integration framework; integrated assessments consist of four phases (I-IV) with inventory phase (II) drawing data from subordinate TEA and LCA results; integrated assessments support decision-making that can lead to further technology maturation within research, development and deployment (RD\&D); further iterations of TEA and LCA with subsequent integration can follow to support new decision-making problems.

Goal and Scope (I). The integration goal needs to clearly state the motivation for the integration of TEA and LCA and articulate the decision-problem. This should include a detailed description of the purpose that drives the practitioner. A statement about the type of expected results and how these will be used helps methodological choices in the scope. In this regard, it is important that 
the goal reflects the motives and distinct roles of commissioner, practitioner and target audience of the integrated assessment. Three different relationships of these roles can be identified as depicted in Figure 3. Each relationship is defined by a different interdependency of the roles, which needs to be accounted for when setting the integration goal. This signifies that two assessments of the same technology can differ when the practitioner is influenced by the commissioner in terms of limited resources or by the target audience regarding the leading question and how to properly present results. For example, in a company, a typical goal of the senior management (joint role of target audience and commissioner) could be the ranking of two investment alternatives. In this case, an engineer (integration practitioner) is tasked to enable a quick decision by limiting the integrated assessment to a set of two weighted criteria. Prior to this point however, the engineer was solely responsible for developing and assessing the alternatives (three joint roles), and therefore selected a different integration approach that supported the detailed analysis of hotspots following a multitude of different criteria. In this regard, the integration type selected should reflect the individual character of the integration goals.

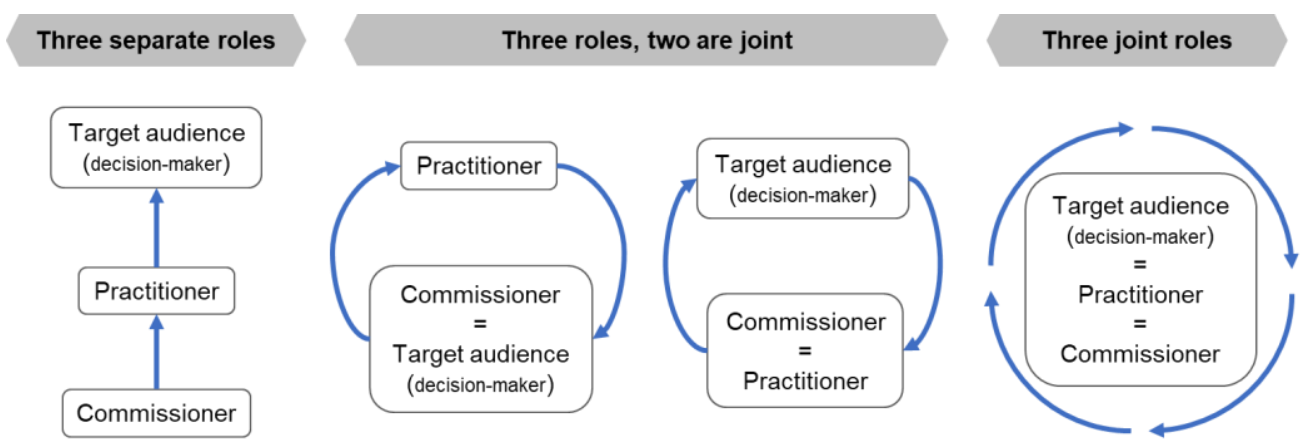

Figure 3: The three roles in assessment (commissioner, practitioner, target audience) and their possible relationships

As the integrated assessment depends on the underlying characteristics of the subordinate TEA and LCA, further sub-goals can be defined to add direction to these studies. The integration scope operationalizes the goal by defining the integration type and the data from TEA and LCA needed for the integration. Dependent on the aim of the integration, it is not required that subordinate TEA and LCA have been carried out simultaneously and on the same base data. Therefore, the integration scope needs to define the allowed uncertainty caused by the level of data alignment. It is key to understand the scope definition of each study to judge the level of their alignment regarding system boundaries, selected benchmark for comparison and underlying technical data in the form of material and energy flows. Differences in scope can affect choices in how an integration can be carried out.

Inventory (II). The integration inventory largely consists of the (intermediate) results of the subordinate assessments, at least one TEA and at least one LCA which can be either conducted in parallel as one overall study or in separate studies The integration approach set in the goal and scope guides the data selection in terms of data type, level of detail and alignment. If the required data cannot be provided, either the subordinate assessments need to be adapted accordingly, or the integration goal needs to be adapted to the available data.

Impact Calculation (III). The impact calculation phase serves to select and optionally transform the TEA and LCA indicator results from the integration inventory to prepare the subsequent interpretation. In its most basic form, this is the core activity of qualitatively selecting and presenting all information to be discussed, thus narrowing down the inventory. If the discussion is not sufficient for the integration goal, further processing of these indicators to new combined 
indicators or MCDA can be included. Combined indicators merge criteria of TEA and LCA, thus creating a new, combined criterion, for example, the calculation of $\mathrm{CO}_{2}$ abatement cost. Another option is the normalization and weighting of separate indicators as well as of combined indicators to allow aggregating TEA and LCA results to a single indicator. This concept is formalized in MCDA. While LCA places MCDA in the interpretation phase, the integration activity includes MCDA in the impact calculation phase, as it returns a new result which is later interpreted.

Interpretation (IV). The interpretation ultimately prepares the decision under both economic and environmental aspects. Interpretation is key to an integrated assessment, as it increases the understanding of the underlying trade-offs and interactions between economic and environmental indicators. Therefore, interpretation should encompass a detailed and transparent discussion of the collected or calculated indicators, concluded by a recommendation. Furthermore, quality and consistency checks of the integrated results, as well as uncertainty and sensitivity analyses, should be performed to illustrate the representativeness and reliability of the discussed results.

\subsection{Part II - integration types}

The analysis revealed different approaches to combining TEA and LCA results. In some cases, a simple reporting of results without interpretation of how the two dimensions are linked is sufficient. In other cases, such linkages are specifically investigated in detailed discussions including numerically combining indicator results. Therefore, how should practitioners decide what type of integration is necessary to meet the objectives of the target audience regarding its decisionmaking problem?

The framework distinguishes between two main categories of combined TEA and LCA: Reporting and Integration. 'Integration' studies are characterized by the superordinate assessment intensively linking TEA and LCA results. Studies without such linking are considered as 'Reporting' of results. The 'Reporting' and 'Integration' categories can be further subdivided into types. This subdivision does not imply any hierarchy, as the suitability of each integration type depends on the integration goal. The Reporting category consists of the types 'separate reporting' and 'coreporting'. The Integration category consists of three types: qualitative discussion ('Type A'), quantitative integration via combined indicator ('Type B'), quantitative integration including preferences ('Type C'). Each category and type have distinguishing characteristics and criteria with increasing specificity, as illustrated in Figure 4.

There are two decisive differences between Reporting and Integration. First, for a study to be integrated, the data selected from each subordinate TEA and LCA must be sufficiently aligned according to what is stated by the goal (criterion 3, Figure 4). However, this framework refrains from considering a full alignment in terms of identical system boundaries, assumptions, and technical inventory as mandatory for integration, as long as the required level of data alignment, according to what is expected by the goal of integration, is achieved. Second, the linkage of the TEA and LCA indicator results must be discussed and interpreted in detail (criterion 4, Figure 4).

Separate reporting. This is the simplest type of combining TEA and LCA as it only requires that the subject of each assessment is sufficiently similar, meaning that the same process has been assessed - separate reporting must fulfill criterion 1 (Figure 4). In separate reporting, the indicators are discussed separately but not compared or linked in a discussion. The decisionmaker is not provided with comparisons and conclusions. Separate reporting was not identified among the analyzed literature, as the search query did not allow finding reporting of single assessments in separate documents. 
Co-reporting. In this type, TEA and LCA results are reported together, for example coinciding within the same document - co-reporting must fulfill the criteria 1-2, (Figure 4). However, the individual studies can be created independently. It is expected that the co-reporting study would consist of separate discussions of environmental and economic indicators, optionally followed by only a very limited discussion (few sentences) linking economic and environmental results of any element of the system or the overall system.

Qualitative discussion-based integration (Type A). Here, a detailed discussion qualitatively compares economic and environmental results - Type A must fulfill the criteria 1-4 (Figure 4). The discussion entails a link or relationship being made between LCA and TEA indicator results of certain system elements, such as identified hotspots, or of obtained Pareto-curves depicting a multitude of scenario outcomes. The term 'qualitative' shall imply, that for the integration activity no additional numeric information is created, despite discussing quantitative results. Qualitative discussion can include the whole process, hotspots in sub-processes and/or tradeoffs as required to achieve the integration goal. In this type of integration, the overall system boundaries of the separate TEA and LCA studies can differ, but those system elements selected for integration need to be suitably aligned in scope for the discussion to be meaningful.

Quantitative combined indicator-based integration (Type B). For Type B the key integration aspect is the calculation of a combined economic and environmental indicator, for example, cost of $\mathrm{CO}_{2}$ abated - Type B must fulfill the criteria 1-5 (Figure 4). The calculated combined indicator mathematically relates TEA and LCA via division of their indicator results. The term 'quantitative' refers to the numeric activity that achieves integration, not the use of quantitative data. As a numerical value is produced, the scope of the subordinate studies must be sufficiently aligned so that additional errors are limited. Type B integration is generally conducted for the whole process, not single system elements, allowing alternative processes to be compared.

Quantitative preference-based integration (Type C). For Type $C$ the key integration aspect is the inclusion of the decision-maker's preferences to prepare a concrete decision based on aggregating the subordinate TEA and LCA results, in other words weighting each criterion and summing them up into a new single value - Type C must fulfill the criteria 1-6 (Figure 4). The quantitative (numeric) link in Type $C$ is achieved via a multi-criteria decision analysis (MCDA). With sufficient alignment of TEA and LCA, MCDA can be performed on the whole process or subprocesses within the system elements identified as hotspots. MCDA can also include the use of combined indicators from Type $B$. It is outside the scope of this work to recommend specific MCDA methods, as the method chosen should be based on the specific goal and scope of each study. Guidance on choosing MCDA methods can be found in literature (Guitouni and Martel, 1998; Jaini and Utyuzhnikov, 2017; Parnell et al., 2013; Serna et al., 2016; Steele et al., 2009; Wątróbski et al., 2019). 


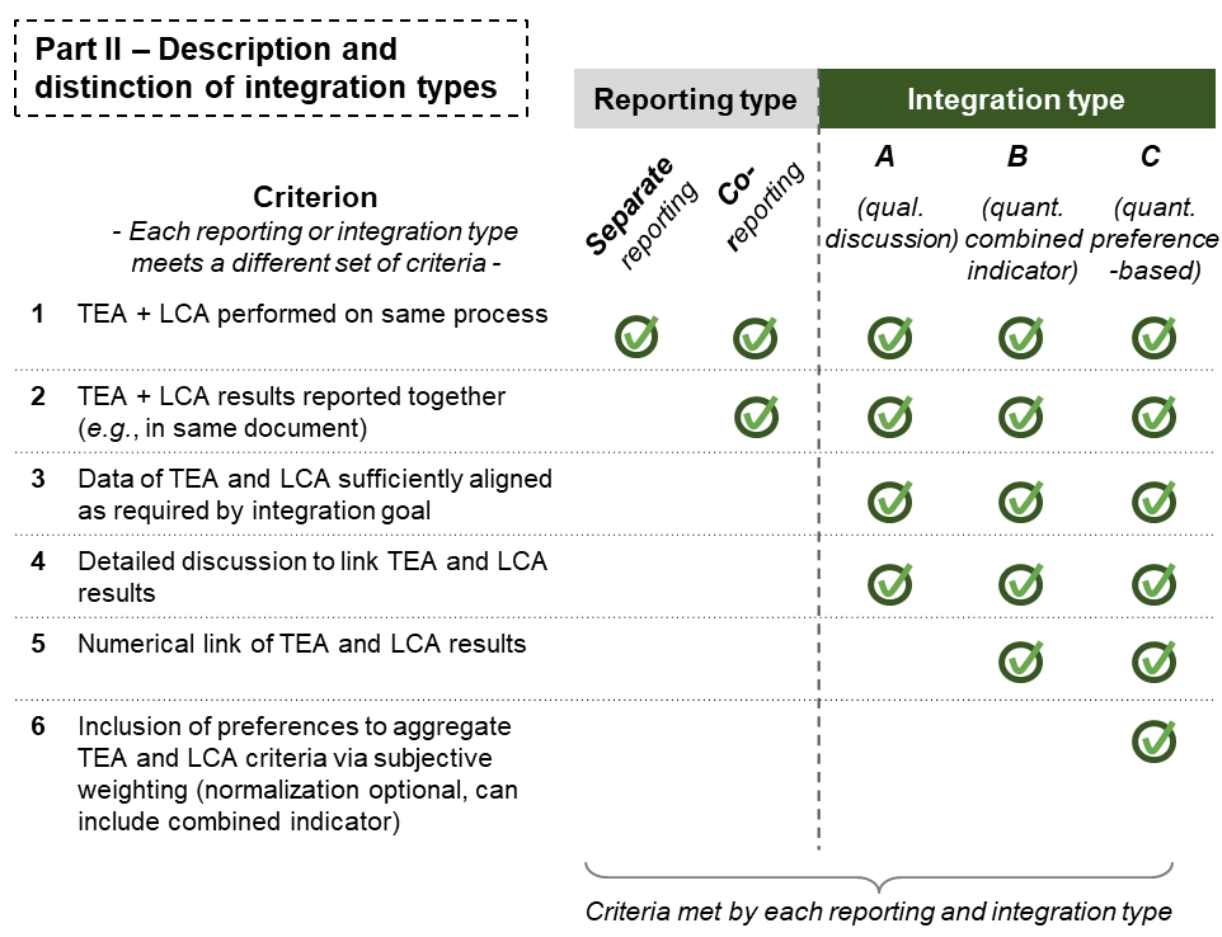

Figure 4: Part II of the integration framework; Criteria matrix to distinguish between two reporting types and three TEA and LCA integration types (e.g., if only criteria 1-2 are met, then it is only co-reporting, not integration; if criteria 1-5 are met, then it is Type B integration); integrated assessments are required to meet at least criteria 1-4

\subsection{Part III - how to select the integration type}

Whether it is necessary to conduct an integrated assessment instead of only reporting separate TEA and LCA results depends on the leading question of the target audience. If integration is required, the purpose of the assessment is to provide meaningful information that helps to solve this leading question. The selection of an integration type should be carried out as part of the integrated assessment's goal and scope phase. Considering there can be a variety of potential goals, the practitioner faces the decision which of the integration types $A, B$, or $C$ is most suitable. Three criteria can be identified which govern the selection of the appropriate integration type and these can be approached as three steps (see Figure 5):

1) The purpose of the integrated assessment,

2) Potential restrictions imposed by technology maturity (TRL),

3) Available resources. 


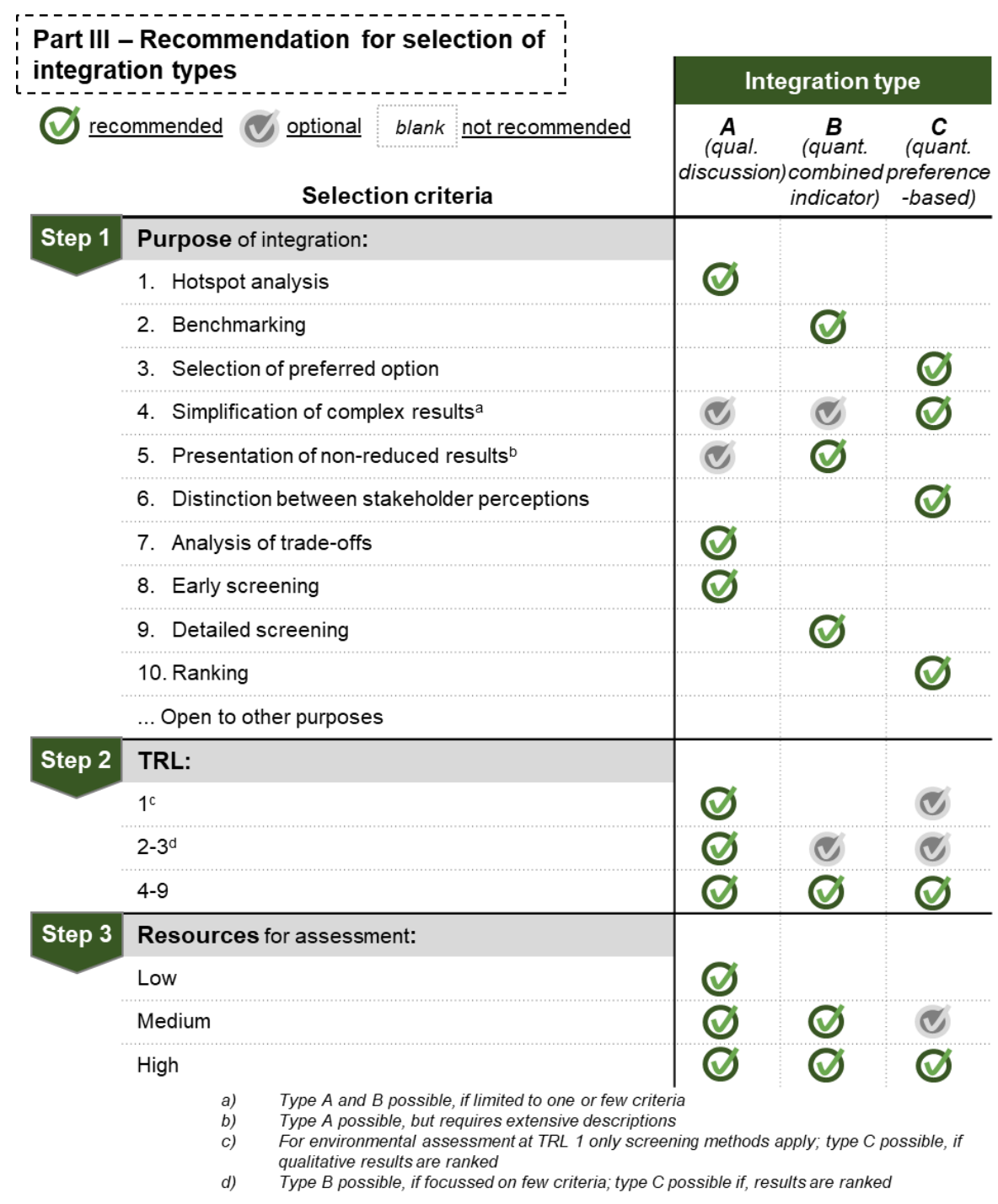

Figure 5: Part III of integration framework; Three-step approach to select a suitable integration type $(A, B, C)$ according to the purpose of the assessment, TRL and resources for the assessment; marks indicate which type is recommended

Step 1) Select the integration type according to the purpose of the assessment. The first step for selecting an integration type is a clear definition of the purpose of the integrated assessment. Although practitioners are generally free to select any integration type for the identified purpose, the three Types are not equally recommended for all purposes. The list of purposes is not exhaustive and different perspectives on integration are possible. It should be noted that integrated studies can have multiple purposes and therefore a mixture of integration types.

1. Hotspot analysis. Type A integration (qualitative discussion-based) is recommended as hotspot analysis requires a discussion of the interlinkages between the parameters that are most influential. Here, integration should be limited to a qualitative discussion via Type A. A quantitative integration via Type $B$ (combined indicator-based) or Type $C$ (preferencebased) would create new numeric results. These would no longer visibly show the full information about the underlying indicator results which are needed to enable decision making at the hotspot. 
2. Benchmarking. Type B integration (combined indicator-based) is recommended if the target audience is interested in a single criterion to compare a technology to its benchmark. The selected combined indicator is a relative, normalized value indicating the relationship of certain economic to environmental impacts, thereby overcoming complexity and enabling quick interpretation across technology fields. Such indicators are valuable for future comparisons based on generally accepted indicators, such as carbon abatement cost.

3. Selection of preferred option. Type C integration (preference-based) is recommended when considering multiple indicators and process options. Multi-criteria decision analysis (MCDA) is used for subjective weightings of criteria and aggregation of multiple indicator results. A single number will be returned that can be interpreted with a single indication, thus supporting the decision based on preferences. A prominent example is the preparation of a concrete investment decision for the deployment of a technology.

4. Simplification of complex results. Type $C$ integration (preference-based) is recommended if a reduced and easy to grasp information basis is desired for decisionmaking. Type $\mathrm{C}$ integration facilitates this by applying MCDA for subjective weighting and aggregation of various criteria and results to a single number. In addition, Type A (qualitative discussion-based) and Type B (combined indicator-based) are optional for integration in this case, if the integrated assessment can be limited to one criterion or few criteria to also achieve the desired simplification.

5. Presentation of non-reduced results. Type B integration (combined indicator-based) is recommended for a simplified presentation of results while keeping information about the original indicator units (non-reduced). This purpose is often found in academic publications or studies with a diverse target audience. As combined indicators are innately relative results, the presentation of intermediate results to show absolute values is often desired in addition. In this case, Type A integration (qualitative discussion) is optional to present results in their original form as non-reduced depiction, for example graphically via Pareto curves.

6. Distinction between stakeholder perceptions. Type $C$ integration (preference-based, MCDA) is recommended if the purpose of the assessment is to distinguish the views of different stakeholders towards a technology. By repeating the MCDA process with different sets of preferences, for example of different stakeholders, the effect of different weighting schemes on the indicated decision can be analyzed.

7. Analysis of trade-offs. Type A integration (qualitative discussion-based) is recommended if the task in technology development is to choose from a set of technical options that each can have a different contribution to environmental and economic impacts. Integration should be limited to the qualitative discussion of absolute indicator results, optionally entailing the plot of a Pareto curve, to first understand what trade-off between LCA and TEA criteria is caused by each option. The integrated assessment of trade-offs can prepare process optimization which is part of further technology development.

8. Early screening. Type A integration (qualitative discussion-based) is recommended for integration-based screening of multiple technologies at lower technology maturity (TRLs < 4). Type A integration encompasses the collection of nominal information associated with economic and environmental criteria, completed by a qualitative discussion to link the results of TEA and LCA.

9. Detailed screening. Type B integration (combined indicator-based) is recommended for integration-based screening at mid and higher technology maturity (TRLs > 3). The calculation of a combined indicator is generally based on the systematic collection of 
numerical data which is required for detailed screening of technology options if no ranking based on preferences is intended.

10. Ranking. Type C integration (preference-based, MCDA) is recommended to rank alternative scenarios. Generally, the alternatives will be ranked by their ability to reach a targeted goal. If this goal entails multiple criteria, then the MCDA process requires the conversion of TEA and LCA results by normalization and weighting. A screening of the selected alternatives can serve as a prior step to identify the underlying information for the MCDA.

Step 2) Restrictions imposed by technology maturity (TRL). In general, the higher the TRL, the more data are available and the uncertainty of assessments and integration decreases. For the assessment, the 'observed' TRL that reflects the data that are input into the assessment is relevant and decided on by the practitioner in the goal and scope phase. It can be lower than or equal to the 'real' TRL that reflects an unrestricted view on the current maturity of the technology.

TRL 1. Type A integration (qualitative discussion-based) is recommended at TRL 1. By definition, no numerical data are available as the technology innovation only consists of an idea. For environmental assessment, this excludes LCA as a quantitative tool. Nevertheless, environmental screening methods can be applied. TEA at TRL 1 is also limited to a similar qualitative evaluation, therefore integration at TRL 1 is often limited to Type A with qualitative discussions. However, a simple form of Type $\mathrm{C}$ integration (preference-based, MCDA) is applicable at TRL 1. Here, the purpose is limited to a (quantitative) ranking of alternatives based on qualitative information, for example when key aspects of the alternative ideas are evaluated by a red-green color scheme.

TRL 2-3. Type A integration (qualitative discussion-based) is recommended at TRL 2-3 as the discussion of a selected set of TEA and LCA indicators without further transformation is most suitable for the low data availability. Type $B$ integration (combined indicator-based) is optional at TRLs 2-3, as a combined indicator is based on a further transformation of already limited information. Generally, Type B integration should be limited to very few criteria with the least uncertain data. Type $C$ integration (preference-based, MCDA) is optional, as MCDA typically requires substantial information on numerous criteria and imminently loses information in the calculation and aggregation. High uncertainty of data can blur the MCDA result therefore, great care should be taken in the research stages of product development.

TRL 4-9. All integration types are equally recommended in the development and deployment stages (TRLs 4-9). The data availability is sufficiently high for each type and the choice mainly depends on the assessment purpose or resource limitations.

Step 3) Restrictions imposed by resources. Resources for an integrated assessment such as money, time, expertise or brainpower need to be spent wisely to ensure that the uncertainty requirement of the integration stated in the goal and scope phase can be met. If it is found that the level of resources available does not match the types selected in Steps $1 \& 2$, goals and resources should be reviewed to ascertain which can be altered to achieve the outcomes required for decision-making.

Low resources. Type A (qualitative discussion-based) is recommended where resources are limited, as only indicators of TEA and LCA need to be selected and discussed, thereby reducing any additional effort of quantitatively linking these indicators. 
Medium resources. Type $A$ and the numerical evaluations proposed in Type $B$ (combined indicator-based) are recommended for a medium set of resources. Type $C$ (preferencebased) is optional as MCDA usually necessitates a higher level of resources.

High resources. All integration types are recommended. Type C integration with MCDA often requires a long process of feedback cycles and reflection to determine an appropriate weighting scheme and is therefore recommended if a high level of resources is available or if a considerable effort is willing to be made.

\section{Demonstration and discussion}

\subsection{Demonstration of type selection}

To demonstrate the application of the framework it is applied to three generic scenarios that describe exemplary and fictitious practitioners investigating the production of methanol from $\mathrm{CO}_{2}$ (see Figure 6). The practitioners need to decide on a suitable integration type for their individual integration purpose, including the consideration of technology maturity and available resources. The examples illustrate how practitioners can derive the recommended integration type based on which criteria of the integration framework are met.

In the first example, an academic researcher is looking to assess a laboratory-based photocatalytic process to produce methanol (TRL 2-3). The researchers' goal is to identify economic and environmental hotspots within the process to enhance experimental development. Hence, the researcher structures both TEA and LCA studies to elucidate sub-processes and specific inputs. In the example, a contribution analysis with respect to selected indicators is applied to compare the impacts of alternative photocatalysts. Here, the discussion of the hotspots could conclude, that further research should be concentrated on alternative 1 instead of alternative 2 due to similar contribution to cost at lower environmental impacts (e.g. lower levels of resource depletion). Thus, the purpose of the integration of both studies is to enhance the subsequent experimental design. The required decisions draw on an increased understanding of how the identified hotspots are linked in terms of resulting tradeoffs between TEA and LCA indicators. In this case, it is sufficient to discuss how the (quantitative) TEA and LCA indicators are interdependent and to allow a recommendation for decision-making. The nature of integration may remain qualitative (Type A), as only existing indicators need to be described. In contrast, the creation of combined indicators or a weighted aggregation of results is not needed. To support the qualitative discussion graphically, the researcher could construct Pareto curves depicting the TEA and LCA indicator results of the alternatives. Although the low TRL and limited resource availability indicate both Type A or B integration, type A with qualitative discussion will provide enough information for the researcher to answer the leading question, without over-complication or increased uncertainty due to new information.

In the second example, a technology manager in a company wishes to select the optimal technical design parameters for a demonstration plant producing methanol from $\mathrm{CO}_{2}$ via a thermocatalytic route with $\mathrm{H}_{2}$ produced by water electrolysis. Data are based on pilot plant trials and three alternative process simulations (TRL 6) differing in the selected electrolysis technology (alkaline, proton exchange membrane or solid oxide electrolysis). This indicates that the data reliability and availability will be good, therefore reducing uncertainty for Type B or Type C integration. As resources are not an issue, all three integration types could be applied. Therefore, the choice of integration type will be primarily based on the purpose of the study. Here, the practitioner is tasked to prepare the information basis for a concrete decision by including multiple economic and 
environmental indicator results. The concrete decision shall be prepared by ranking the three alternative options according to the decision-maker's preferences. While the qualitative discussion of the linkage between the indicator results is certainly required for the interpretation of the derived conclusions, the integration approach needs to aggregate these results into a single value, thereby providing additional information. Therefore, MCDA instruments can be applied to identify the optimal system, indicating preference-based integration (Type C).

In the third example, a policy advisor is looking to compare viable routes to produce fossil-free low GHG emission methanol for the chemical industry. This indicates the purpose is benchmarking options against each other. The processes to be assessed range in maturities from TRLs 3-8, and only routes that exhibit the potential of lower greenhouse gas emissions compared to the fossilbased route are of interest. It is the goal to identify the route with the biggest economic lever to reduce environmental impacts. A simple, preferably non-subjective instrument is required to communicate the benchmark results to a diverse target audience. Here, benchmarking suggests a Type B integration (combined indicator), as it results in a single criterion combining economic and environmental criteria without entailing weighting schemes. The policy advisor could conclude that the cost of carbon abated is a suitable combined indicator to compare the routes. Furthermore, data and resource availability indicate that Type C may not be appropriate as limitations on both data and resources are present. Therefore, the overall recommendation is Type B integration (combined indicator). 


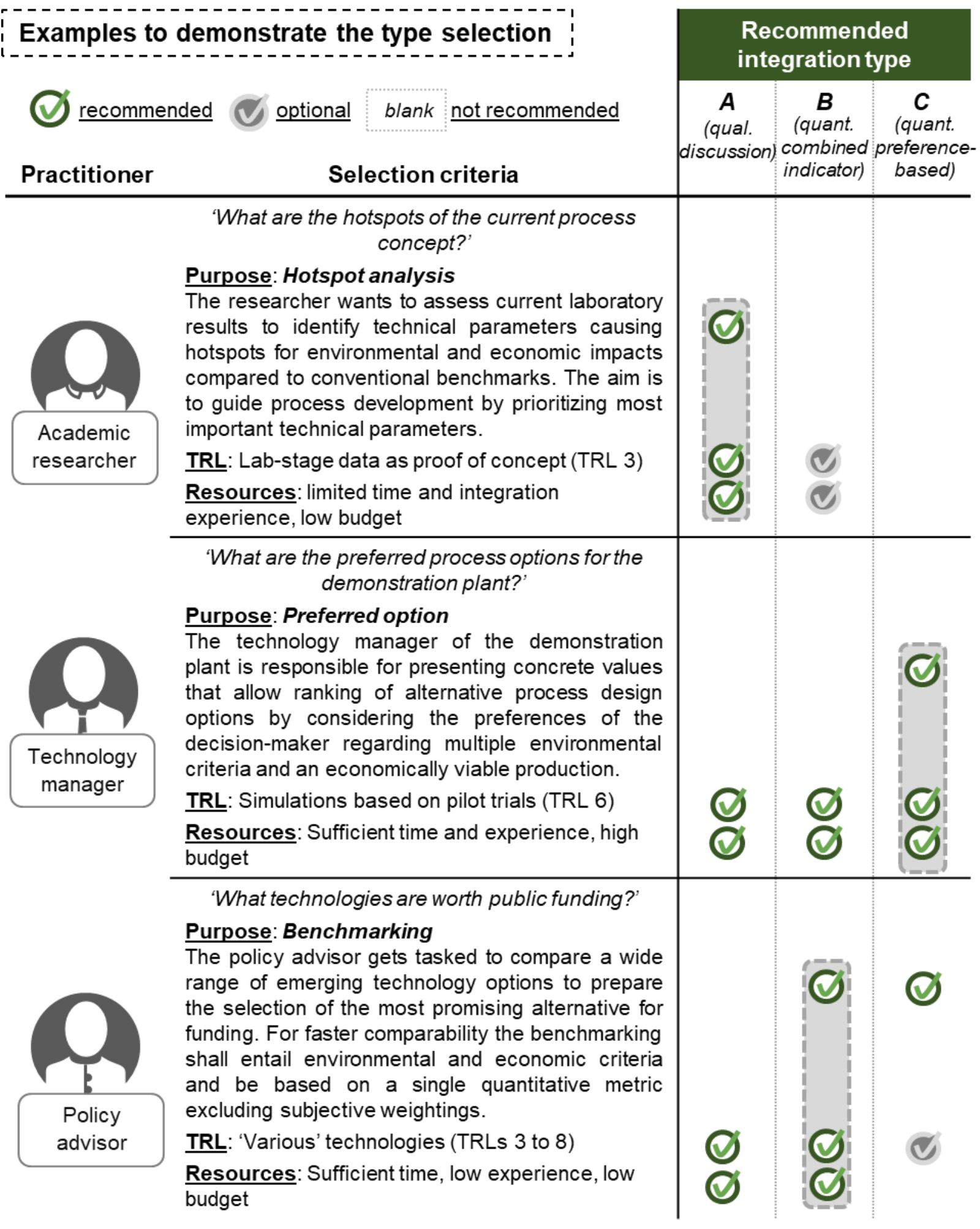

Figure 6: Selection of a suitable integration type demonstrated by three exemplified integration practitioners

\subsection{Discussion of framework}

The focus of the proposed framework is on the integrated assessment of chemical technologies in development. This decision was made for three reasons: 1) the transition towards green 
chemistry requires a continuous assessment of the developed innovations, 2) TEA and LCA approaches for this field show a similar enough structure for alignment and integration, and 3) this field experiences a lack of guidance for integrating assessments. It is also acknowledged that the framework could be adapted for other technology fields and to include further assessment types (for example, social acceptance assessment).

In Part I, the definition of the multi-layer assessment approach places integration as a superordinate assessment over subordinate TEA and LCA. This has not been formulated as such before in the related literature. Integration is here defined as a distinct assessment with four phases: goal and scope (I), inventory (II), impact calculation (III), interpretation (IV). Therefore, a targeted and transparent discussion of critical integration aspects along the assessment phases is possible.

An adequate definition of the integration goal is found to be lacking in most studies of the literature analysis. Accordingly, the framework emphasizes the importance of understanding clearly the purpose of the integrated assessment which is key to selecting an appropriate integration type. A statement of generic goals such as 'to identify economic and environmental impacts' does not sufficiently reflect the purpose. Therefore, the framework guides the practitioner to include meaningful purposes in the goal, such as 'to analyze the hotspots in the process for further optimization by engineers' or 'to enable policy makers to identify processes with the cheapest carbon abatement cost'. This guided goal setting enables subsequent methodological choices.

The inventory of an integrated assessment is fed by indicator results of the subordinate TEA and LCA. Hence, an understanding of the similarities and differences of TEA and LCA principles is critical. This can be achieved by taking a closer look at how both assessments are performed along their similar four phases (I-IV), as will be done in the following:

- Goal and scope (phase I) of TEA and LCA serve the same general purpose so that similar principles guide the distinct methodological choices. However, the selection of benchmarks for comparison within each assessment can be driven by deviating perspectives, resulting in deviating assumptions for the underlying data. An example would be the selection of the most economic benchmark in TEA which might not be the most environmentally friendly, as would be required for the LCA benchmark. Thus, if the integrated assessment discusses the performance of the technology, the benchmarks need to be identical.

- The inventory (phase II) of TEA differs from LCA inventory in three major aspects: i) there is no single, unambiguous correlation of physical flows with monetary flows; ii) the correlation can be non-linear, for example, material costs do not need to linearly increase with an increased material flow, as would be the assumption for environmental impacts; iii) conceptual flows with no physical representation can have monetary impacts, such as taxes, purchase price premiums or customer demand fluctuation affecting the selling price. Accordingly, this inherent difference in data formation and composition should be paid attention to when identifying any potential bearings on the uncertainty of the integrated TEA and LCA results.

- The impact calculation (phase III) in TEA and LCA shows methodological differences posing additional challenges for interpreting integrated results. The units of indicators are different and prevent a simple aggregation of results. TEA often considers dynamic indicators to include time preference, whereas LCA impacts are often considered static. 
- The interpretation (phase IV) in TEA and LCA again follows a similar generic approach, although decision-makers reading an integrated assessment need to be aware of the underlying reasons for uncertainty, for example, if data are more reliant on market dynamics than on physical flows.

Part II of the framework introduces three newly defined integration types $(A, B, C)$, which are the basis for the phases of impact calculation (III) and interpretation (IV). These type definitions were tested to validate their fit with existing integrated studies. Firstly, the types were determined for the analyzed set of 70 papers, then further validation was carried out against a sample for a specific technology field. The field of $\mathrm{CO}_{2}$ utilization technologies (Styring et al., 2015) was chosen, as integration of LCA and TEA has been highlighted as a desirable assessment tool for this area (Mission Innovation, 2017; Müller et al., 2020; Sick et al., 2019; Zimmermann et al., 2020a, 2020b). From the non-reduced literature set of 711 papers, 25 papers met the required criteria of containing both an economic and environmental assessment and covering $\mathrm{CO}_{2}$ utilization (a summary of the results is found in the Electronic Supporting Information). Therefore, considering both sets together a total of 95 papers were analyzed. The distribution across the integration and reporting types is presented in Figure 7. No papers were found that could not be fitted to one of the types. However, the type 'separate reporting' is not included, as all papers were screened to include both an economic and environmental assessment. In both literature sets, co-reporting and Type $\mathrm{C}$ integration (preference-based) are most prevalent. However, in the smaller set of $\mathrm{CO}_{2}$ utilization literature, a fairly uniform distribution of reporting and integration types is observed.

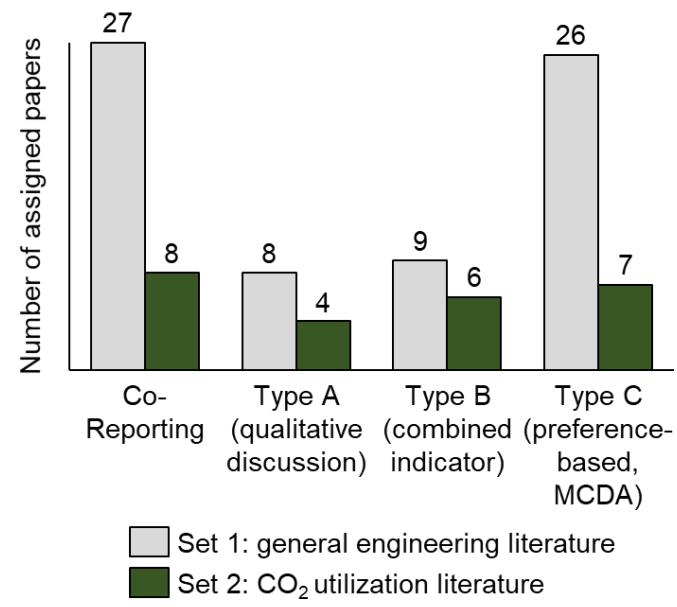

Figure 7: Distribution of identified reporting and integration types across two sets of analyzed literature; Set 1 is the sample of 70 randomly selected studies from a non-reduced set of 711 papers, Set 2 is the field-specific validation set containing all 25 studies within the non-reduced set of 711 papers matching the concept of $\mathrm{CO}_{2}$ utilization

Part II of the framework further presents a criteria matrix (see Figure 4) to distinguish the reporting and integration types. These criteria can be applied in a straightforward fashion. An exception is criterion 3 that demands sufficient alignment of TEA and LCA data in accordance with the integration goal. While TEA and LCA results contribute inherent uncertainty to the final integration result, additional integration uncertainty is correlated inversely with the alignment of TEA and LCA data, as depicted in Figure 8. In general, a higher degree of alignment lowers additional uncertainty. The highest level of uncertainty is theoretically introduced when TEA and LCA would rely on entirely different data; the lowest level of uncertainty follows from TEA and LCA that rely on the same data wherever possible. Criterion 3 can only be met if the level of alignment reflects the accepted uncertainty of integration defined by the goal and scope. In contrast, some proposed 
frameworks in literature demand full alignment as the leading criterion to be met for assessments to be integrated (Azapagic et al., 2006; Miah et al., 2017; Serna et al., 2016; Thomassen et al., 2019). In those cases, the specified set of data would need to be common for both TEA and LCA. The methodology described here does not require a full or a pre-determined degree of alignment of TEA and LCA data for meaningful integration. An adequate degree of alignment follows the integration goal: the degree of alignment needs to be such that the uncertainty obtained in the final, integrated result is in line with the uncertainty requirement implied in the integration goal. Therefore, the framework is flexible enough to apply to any goal that is set; and does not cater to a specific level of uncertainty that is pre-determined by the way the integration is performed (i.e., fixing which data basis have to be common for both TEA and LCA).

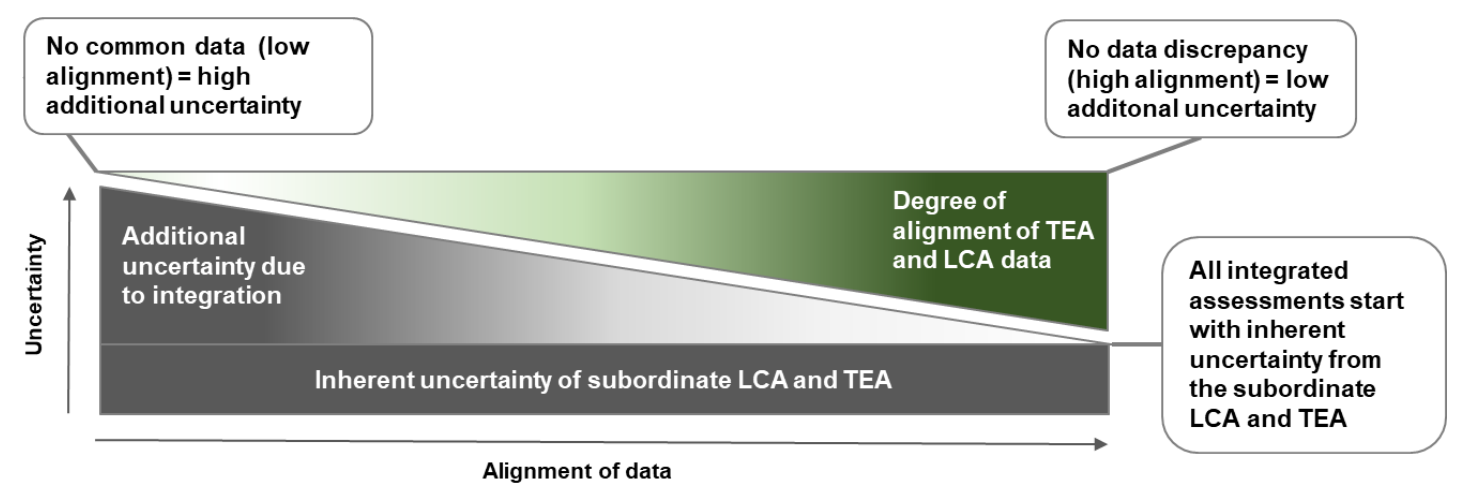

Figure 8: Inverse relationship between the alignment of scope and data between TEA and LCA and acceptable additional uncertainty caused by integration.

Part III of the framework proposes the three-step procedure to select a suitable integration type which is designed in a way that other purposes can easily be added. We hereby acknowledge that the specific environments, tasks, and circumstances that practitioners find themselves in can vary substantially. To make sure the framework can be applied right away by practitioners without substantial prior experience, the proposed restrictions set by technology maturity ( $T R L)$ and resources are kept at a low level of granularity. However, advanced practitioners may benefit from expanding the framework by including a finer differentiation of the nine TRLs for data availability or additional categories allowing finer sorting of the level of resources.

Overall, the specificity of the proposed framework seeks to provide a balanced level that is, on the one hand, detailed enough to give strong guidance, and on the other hand, open and flexible enough to serve stakeholders with different backgrounds regarding experience, skill, function, and mission. No suggestion for concrete indicators is included and no normalization references or weighting schemes for MCDA are proposed. Whilst such specification could facilitate the comparison of different integrated assessments, it is necessary to leave this level of specification to the practitioner: due to the unique goal and scope of each integrated assessment, appropriate choices for one may not be appropriate for another. Practitioners should choose methodological options such as selected (combined) indicators, normalization, weightings, or MCDA methodologies, based on the advantages and disadvantages of each method with respect to the integration goal. Specifying a discrete range of such options would be detrimental to the flexibility and applicability of the framework. 


\section{Conclusion}

TEA and LCA have proven to be valuable tools for interpreting impacts separately in regard to different criteria, however, properly integrating them can effectively enhance decision-making. The proposed integration framework increases the knowledge basis by providing a methodology that defines TEA and LCA as subordinate assessments linked by a superordinate integrated assessment. Integration can only support decision-makers if it is understood as individual assessment providing additional insights linking the LCA and TEA reports. The framework provides practitioners with step-by-step guidance through the four phases of integration and can quickly be adopted due to its familiarity with LCA and TEA methodologies.

Integration can only be achieved by interpreting the link between TEA and LCA as the main criterion, thus avoiding mere reporting of results. A one-size-fits-all solution for integration would force practitioners to make an identical methodological choice for varying goals. Therefore, the framework derives three types of integration characterized by: the limitation to a qualitative discussion (Type A), the calculation of combined indicators (Type B) or the inclusion of preferences via multi-criteria decision analysis (Type $\mathrm{C}$ ). Here, practitioners are guided by the presented step-by-step approach for choosing a suitable integration type. It allows for type selection according to the intended integration purpose as well as restrictions imposed by technology maturity and resource availability. By developing a widely adopted understanding of integrated assessments, it can be ensured that decisions will no longer be based on either an economic or an environmental criterion in isolation, but on highlighting their interlinkages. Furthermore, in the future, the framework could be expanded to include social sustainability metrics by incorporating assessments such as SLCA. However, if SLCA results are of qualitative nature, then combined indicator-based integration (Type B) would not be supported.

This framework helps to expedite advances in sustainable chemical technology development, as it provides a consistent understanding of integration to assist diverse stakeholders in selecting a suitable integration methodology.

\section{Conflicts of interest}

The authors do not declare a conflict of interest.

\section{Acknowledgement}

We thank the $\mathrm{CO}_{2}$ nsistent project team for fruitful discussions. Funding: This work was supported by the European Institute of Technology (EIT) Climate-KIC (Project code 200281); the Deutsche Bundesstiftung Umwelt (DBU); the German Federal Ministry of Education and Research (BMBF); the Global $\mathrm{CO}_{2}$ Initiative at The University of Michigan; the Engineering and Physical Sciences Research Council (EPSRC) through the CO2Chem Network (Project number EP/P026435/1). 


\section{References}

Azapagic, A., Millington, A., Collett, A., 2006. A methodology for integrating sustainability considerations into process design. Chem. Eng. Res. Des. 84, 439-452. https://doi.org/10.1205/cherd05007

Bernier, E., Maréchal, F., Samson, R., 2010. Multi-objective design optimization of a natural gascombined cycle with carbon dioxide capture in a life cycle perspective. Energy 35, 11211128. https://doi.org/10.1016/j.energy.2009.06.037

Buchner, G.A., Stepputat, K.J., Zimmermann, A.W., Schomäcker, R., 2019. Specifying Technology Readiness Levels for the Chemical Industry. Ind. Eng. Chem. Res. 58, 69576969. https://doi.org/10.1021/acs.iecr.8b05693

Buchner, G.A., Zimmermann, A.W., Hohgräve, A.E., Schomäcker, R., 2018. Techno-economic Assessment Framework for the Chemical Industry - Based on Technology Readiness Levels. Ind. Eng. Chem. Res. 57, 8502-8517. https://doi.org/10.1021/acs.iecr.8b01248

Chao, H., Agusdinata, D.B., DeLaurentis, D.A., 2019. The potential impacts of Emissions Trading Scheme and biofuel options to carbon emissions of U.S. airlines. Energy Policy 134, 110993. https://doi.org/10.1016/j.enpol.2019.110993

CWRT, 1999. Total Cost Assessment Methodology - Internal Managerial Decision making Tool. Center for Waste Reduction Technologies, American Institute of Chemical Engineers, New York.

Di Maria, A., Eyckmans, J., Van Acker, K., 2018. Downcycling versus recycling of construction and demolition waste: Combining LCA and LCC to support sustainable policy making. Waste Manag. 75, 3-21. https://doi.org/10.1016/j.wasman.2018.01.028

European Commission - Joint Research Centre - Institute for Environment and Sustainability, 2010. International Reference Life Cycle Data System (ILCD) Handbook - General guide for Life Cycle Assessment - Detailed guidance. Publications Office of the European Union, Luxembourg. https://doi.org/10.2788/38479

Finkbeiner, M., Schau, E.M., Lehmann, A., Traverso, M., 2010. Towards Life Cycle Sustainability Assessment. Sustainability 2, 3309-3322. https://doi.org/10.3390/su2103309

García-Velásquez, C.A., Cardona, C.A., 2019. Comparison of the biochemical and thermochemical routes for bioenergy production: A techno-economic (TEA), energetic and environmental assessment. $\quad$ Energy 232-242. https://doi.org/10.1016/j.energy.2019.01.073

García, N., Fernández-Torres, M.J., Caballero, J.A., 2014. Simultaneous environmental and economic process synthesis of isobutane alkylation. J. Clean. Prod. 81, 270-280. https://doi.org/10.1016/j.jclepro.2014.06.016

Gargalo, C.L., Carvalho, A., Gernaey, K. V., Sin, G., 2017. Optimal Design and Planning of Glycerol-Based Biorefinery Supply Chains under Uncertainty. Ind. Eng. Chem. Res. 56, 11870-11893. https://doi.org/10.1021/acs.iecr.7b02882

Guinée, J.B., Gorrée, M., Heijungs, R., Huppes, G., Kleijn, R., Koning, A., de Oers, L., van Wegener Sleeswijk, A., Suh, S., de Haes, H.A.U., 2002. Handbook On Life Cycle Assessment Operational guide to the ISO standards. Kluwer Academic Publishers, Dordrecht. 
Guinée, J.B., Heijungs, R., Huppes, G., Zamagni, A., Masoni, P., Buonamici, R., Ekvall, T., Rydberg, T., 2011. Life cycle assessment: past, present, and future. Environ. Sci. Technol. 45, 90-96. https://doi.org/10.1021/es101316v

Guitouni, A., Martel, J.M., 1998. Tentative guidelines to help choosing an appropriate MCDA method. Eur. J. Oper. Res. 109, 501-521. https://doi.org/10.1016/S0377-2217(98)00073-3

Halog, A., Manik, Y., 2011. Advancing integrated systems modelling framework for life cycle sustainability assessment. Sustainability 3, 469-499. https://doi.org/10.3390/su3020469

Hoogmartens, R., Van Passel, S., Van Acker, K., Dubois, M., 2014. Bridging the gap between LCA, LCC and CBA as sustainability assessment tools. Environ. Impact Assess. Rev. 48, 27-33. https://doi.org/10.1016/j.eiar.2014.05.001

Hunkeler, D., Lichtenvort, K., Rebitzer, G., 2008. Environmental life cycle costing. CRC Press.

Ibáñez-Forés, V., Bovea*, M.D., Pérez-Belis, V., 2014. A holistic review of applied methodologies for assessing and selecting the optimal technological alternative from a sustainability perspective. J. Clean. Prod. 70, 259-281. https://doi.org/10.1016/j.jclepro.2014.01.082

International Organization for Standardization Geneva, Switzerland, 2006a. ISO EN 14040: 2006. International Organization for Standardization Geneva, Switzerland, 2006b. ISO EN 14044: 2006.

Jaini, N., Utyuzhnikov, S., 2017. Trade-off ranking method for multi-criteria decision analysis. J. Multi-Criteria Decis. Anal. 24, 121-132. https://doi.org/10.1002/mcda.1600

Khatiwada, D., Venkata, B.K., Silveira, S., Johnson, F.X., 2016. Energy and GHG balances of ethanol production from cane molasses in Indonesia. Appl. Energy 164, 756-768. https://doi.org/10.1016/j.apenergy.2015.11.032

Lu, H.R., El Hanandeh, A., 2019. Life cycle perspective of bio-oil and biochar production from hardwood biomass; what is the optimum mix and what to do with it? J. Clean. Prod. 212, 173-189. https://doi.org/10.1016/j.jclepro.2018.12.025

Marler, R.T., Arora, J.S., 2004. Survey of multi-objective optimization methods for engineering. Struct. Multidiscip. Optim. 26, 369-395. https://doi.org/10.1007/s00158-003-0368-6

Mata, T.M., Caetano, N.S., Martins, A.A., 2015. Sustainability evaluation of nanotechnology processing and production. Chem. Eng. Trans. 45, 1969-1974. https://doi.org/10.3303/CET1545329

Merriam-Webster.com Dictionary, 2020a. "Integration." [WWW Document]. Merriam-Webster. URL https://www.merriam-webster.com/dictionary/integration (accessed 2.21.20).

Merriam-Webster.com Dictionary, 2020b. "Alignment." [WWW Document]. Merriam-Webster. URL https://www.merriam-webster.com/dictionary/alignment (accessed 2.21.20).

Merriam-Webster.com Dictionary, 2020c. "Combining." [WWW Document]. Merriam-Webster. URL https://www.merriam-webster.com/dictionary/combining (accessed 2.21.20).

Merriam-Webster.com Dictionary, 2020d. "Aggregation.” [WWW Document]. Merriam-Webster. URL https://www.merriam-webster.com/dictionary/aggregation (accessed 2.21.20).

Miah, J.H., Koh, S.C.L., Stone, D., 2017. A hybridised framework combining integrated methods for environmental Life Cycle Assessment and Life Cycle Costing. J. Clean. Prod. 168, 846866. https://doi.org/10.1016/j.jclepro.2017.08.187 
Minkov, N., Finkbeiner, M., Sfez, S., Dewulf, J., Manent, A., Rother, E., Weyell, P., Kralisch, D., Schowanek, D., Lapkin, A., Jones, M., Azapagic, A., 2016. Current State of LCSA: MEASURE Roadmap for Sustainability Assessment in European Process Industries Background document.

Mission Innovation, 2017. Accelerating Breakthrough Innovation in Carbon Capture, Utilization, and Storage, Report of the Mission Innovation Carbon Capture, Utilization, and Storage Experts' Workshop.

Moni, S.M., Mahmud, R., High, K., Carbajales-Dale, M., 2020. Life cycle assessment of emerging technologies: A review. J. Ind. Ecol. 24, 52-63. https://doi.org/10.1111/jiec.12965

Müller, L.J., Kätelhön, A., Bachmann, M., Zimmermann, A., Sternberg, A., Bardow, A., 2020. A Guideline for Life Cycle Assessment of Carbon Capture and Utilization. Front. Energy Res. 8, 15. https://doi.org/10.3389/fenrg.2020.00015

Norris, G.A., 2001a. Integrating economic analysis into LCA. Environ. Qual. Manag. 10, 59-64. https://doi.org/https://doi.org/10.1002/tqem.1006

Norris, G.A., 2001b. Integrating life cycle cost analysis and LCA. Int. J. Life Cycle Assess. 6, 118120. https://doi.org/https://doi.org/10.1007/BF02977849

Parnell, G.S., Bresnick, T., Tani, S.N., Johnson, E.R., 2013. Handbook of Decision Analysis. Wiley.

Pastore, B.M., Savelski, M.J., Slater, C.S., Richetti, F.A., 2016. Life cycle assessment of N-methyl2-pyrrolidone reduction strategies in the manufacture of resin precursors. Clean Technol. Environ. Policy 18, 2635-2647. https://doi.org/10.1007/s10098-016-1180-5

Reich, M.C., 2005. Economic assessment of municipal waste management systems - Case studies using a combination of life cycle assessment (LCA) and life cycle costing (LCC). J. Clean. Prod. 13, 253-263. https://doi.org/10.1016/j.jclepro.2004.02.015

Santoyo-Castelazo, E., Azapagic, A., 2014. Sustainability assessment of energy systems: integrating environmental, economic and social aspects. J. Clean. Prod. 80, 119-138. https://doi.org/10.1016/j.jclepro.2014.05.061

Saunders, B., Sim, J., Kingstone, T., Baker, S., Waterfield, J., Bartlam, B., Burroughs, H., Jinks, C., 2018. Saturation in qualitative research: exploring its conceptualization and operationalization. Qual. Quant. 52, 1893-1907. https://doi.org/10.1007/s11135-017-0574-8

Serna, J., Díaz Martinez, E.N., Narváez Rincón, P.C., Camargo, M., Gálvez, D., Orjuela, Á., 2016. Multi-criteria decision analysis for the selection of sustainable chemical process routes during early design stages. Chem. Eng. Res. Des. 113, 28-49. https://doi.org/10.1016/j.cherd.2016.07.001

Sick, V., Armstrong, K., Cooney, G., Cremonese, L., Eggleston, A., Faber, G., Hackett, G., Kätelhön, A., Keoleian, G., Marano, J., Marriott, J., McCord, S., Miller, S.A., Mutchek, M., Olfe-Kräutlein, B., Ravikumar, D., Roper, L.K., Schaidle, J., Skone, T., Smith, L., Strunge, T., Styring, P., Tao, L., Völker, S., Zimmermann, A., 2019. The Need for and Path to Harmonized Life Cycle Assessment and Techno-Economic Assessment for Carbon Dioxide Capture and Utilization. Energy Technol. 1-7. https://doi.org/https://doi.org/10.1002/ente.201901034

Steele, K., Carmel, Y., Cross, J., Wilcox, C., 2009. Uses and Misuses of Multicriteria Decision Analysis (MCDA) in Environmental Decision Making. Risk Anal. 29, 26-33. https://doi.org/10.1111/j.1539-6924.2008.01130.x 
Styring, P., Quadrelli, E.A., Armstrong, K., 2015. Carbon Dioxide Utilisation. Elsevier. https://doi.org/10.1016/C2012-0-02814-1

Swarr, T.E., Hunkeler, D., Klöpffer, W., Pesonen, H.-L., Ciroth, A., Brent, A.C., Pagan, R., 2011. Environmental life-cycle costing: a code of practice. Int. J. Life Cycle Assess. 16, 389-391. https://doi.org/10.1007/s11367-011-0287-5

Tang, Y., You, F., 2018. Multicriteria Environmental and Economic Analysis of Municipal Solid Waste Incineration Power Plant with Carbon Capture and Separation from the Life-Cycle Perspective. ACS Sustain. Chem. Eng. 6, 937-956. https://doi.org/10.1021/acssuschemeng.7b03283

Telsnig, T., Tomaschek, J., Özdemir, E.D., Bruchof, D., Fahl, U., Eltrop, L., 2013. Assessment of selected CCS technologies in electricity and synthetic fuel production for $\mathrm{CO} 2$ mitigation in South Africa. Energy Policy 63, 168-180. https://doi.org/10.1016/j.enpol.2013.08.038

Thomassen, G., Van Dael, M., Van Passel, S., 2018. The potential of microalgae biorefineries in Belgium and India: An environmental techno-economic assessment. Bioresour. Technol. 267, 271-280. https://doi.org/10.1016/j.biortech.2018.07.037

Thomassen, G., van Dael, M., van Passel, S., You, F., 2019. How to assess the potential of emerging green technologies? Towards a prospective environmental and techno-economic assessment framework. Green Chem. 21, 4868-4886. https://doi.org/10.1039/C9GC02223F

Tock, L., Maréchal, F., 2015. Environomic optimal design of power plants with CO2 capture. Int. J. Greenh. Gas Control 39, 245-255. https://doi.org/10.1016/j.jjggc.2015.05.022

Tock, L., Maréchal, F., Perrenoud, M., 2015. Thermo-environomic evaluation of the ammonia production. Can. J. Chem. Eng. 93, 356-362. https://doi.org/10.1002/cjce.22126

van der Sluijs, J.P., 2002. Definition of Integrated Assessment, in: Encyclopaedia of Global Environmental Change. John Wiley \& Sons, Chichester, pp. 249-250.

Velasquez, M., Hester, P.T., 2013. An analysis of multi-criteria decision making methods. Int. J. Oper. Res. 10, 56-66.

Verma, A., Olateju, B., Kumar, A., 2015. Greenhouse gas abatement costs of hydrogen production from underground coal gasification. Energy 85, 556-568. https://doi.org/10.1016/j.energy.2015.03.070

Wątróbski, J., Jankowski, J., Ziemba, P., Karczmarczyk, A., Zioło, M., 2019. Generalised framework for multi-criteria method selection. Omega 86, 107-124. https://doi.org/10.1016/j.omega.2018.07.004

Zhang, W., Gu, F., Dai, F., Gu, X., Yue, F., Bao, B., 2016. Decision framework for feasibility analysis of introducing the steam turbine unit to recover industrial waste heat based on economic and environmental assessments. J. Clean. Prod. 137, 1491-1502. https://doi.org/10.1016/j.jclepro.2016.07.039

Zimmerman, J.B., Anastas, P.T., Erythropel, H.C., Leitner, W., 2020. Designing for a green chemistry future. Science. 367, 397-400. https://doi.org/10.1126/science.aay3060

Zimmermann, A., Müller, L., Wang, Y., Langhorst, T., Wunderlich, J., Marxen, A., Armstrong, K., Buchner, G.A., Kätelhön, A., Bachmann, M., Sternberg, A., Michailos, S., McCord, S., Zaragoza, A.V., Naims, H., Cremonese, L., Strunge, T., Faber, G., Mangin, C., Olfe-Kräutlein, B., Styring, P., Schomäcker, R., Bardow, A., Sick, V., 2020a. Techno-Economic Assessment \& Life Cycle Assessment Guidelines for CO2 Utilization (Version 1.1). University of Michigan 
Library, Ann Arbor, Ml. https://doi.org/10.3998/2027.42/16257

Zimmermann, A., Wunderlich, J., Müller, L., Buchner, G.A., Marxen, A., Michailos, S., Armstrong, K., Naims, H., McCord, S., Styring, P., Sick, V., Schomäcker, R., 2020b. Techno-Economic Assessment Guidelines for $\mathrm{CO} 2$ Utilization. Front. Energy Res. 8, 5. https://doi.org/10.3389/fenrg.2020.00005 